\title{
A Transmission Electron Microscopic Study of Rabbit Liver Sinusoids with Special Remarks on an Experimentally Induced Canalicular System and the "Pored Domes" in the Endothelial Cells
}

\author{
Yutaka TANuma, Masako Ohata and Toshio Ito \\ Department of Anatomy (Prof. K. UchiDA and Prof. T. Iто), Teikyo University School of Medicine, \\ Tokyo, Japan \\ Received December 3, 1986
}

\begin{abstract}
Summary. Rabbits were starved for a week and then allowed to take the standard diet; the animals were sacrificed after 20 or $24 \mathrm{hr}$. One group of the animals was treated in winter, and the other, in summer. Control animals were fed solid rabbit food ad libitum.

In the control rabbits, short rudimentary canaliculi and occasional small-sized pored domes were found in the thicker portions of the endothelial extension. In the animals experimentally treated in winter, well-developed meandering canaliculi with vacuolar expansions and constrictions appeared in the thicker portions and perikaryonal cytoplasm. In addition prominent pored domes were produced. The canaliculi often formed spongelike networks with openings both to the sinusoid and the Disse's space. The development of the canalicular system and pored domes correlated to an increased blood flow through the sinusoids; this seemed to be induced upon sudden feedings after lengthy starvation. The rabbits subjected to the experimental treatment in summer exhibited no distinct development of the canaliculi and pored domes. This result was ascribed to the inhibited functions of the rabbit liver during this season.
\end{abstract}

In our previous transmission electron microscopic (TEM) study on the sinusoidal cells of guinea pig livers (OHATA et al., 1984), we demonstrated a meandering canalicular system in the thicker portion of the cytoplasmic extension and in the perikaryonal cytoplasm of the endothelial cell. In addition, the "pored domes", as first revealed by FUJITA and his collaborators (FUJITA et al., 1976; YOSHINARI and FUJITA, 1982) by scanning electron microscopy (SEM) in the glomerular endothelial cells of the rat and rabbit kidney, were also found in the sinusoidal endothelial perikaryon of guinea pig livers.

In a preliminary survey for the present TEM study on the rabbit liver, however, we could find nothing of such a canalicular system. We therefore subjected the rabbits to such experimental treatment as might induce an accelerated blood flow in the hepatic sinusoids. It was thereby expected that a canalicular structure in the sinusoidal endothelium similar to that in normal guinea pigs might be produced in rabbits. 


\section{MATERIALS AND METHODS}

Nineteen mature rabbits of both sexes, weighing about $2 \mathrm{~kg}$, were used. Of these nine control animals were allowed to take solid rabbit food and water ad libitum (standard diet) during the experiment. The remaining ten animals underwent the experimental treatment, being at first starved for one week, in accordance with the experimental procedure carried out by SATSUKI (1955) in the rabbit, then put on the standard diet and sacrificed after 20 or $24 \mathrm{hr}$. Among the ten treated animals, five were subjected to the experimental treatment in summer (July or August), the other five, in winter (December).

All the animals--both control and treated-were anesthetized with Ketaral, and after laparotomy the liver was perfused via the portal vein with a cold fixative containing $0.1 \mathrm{M}$ phosphate buffered $2.5 \%$ glutaraldehyde ( $\mathrm{pH} 7.4$ ). The liver was then excised to be cut into minute pieces. After $2 \mathrm{hr}$ immersion in the same fixative, they were rinsed several times in a cold $0.1 \mathrm{M}$ phosphate buffer containing $5 \%$ sucrose $(\mathrm{pH}$ 7.4) and left overnight in the same buffer at $5^{\circ} \mathrm{C}$. They were postfixed for $90 \mathrm{~min}$ in a $1 \% \mathrm{OsO}_{4}$ solution in $0.1 \mathrm{M}$ phosphate buffer containing $5 \%$ sucrose $(\mathrm{pH} 7.4)$. Following dehydration in graded ethanol, the tissue pieces were embedded in Quetol 812, and ultrathin sections were prepared with the Porter-Blum Ultra-Microtome MT2-B. These sections were stained with saturated uranyl acetate and Sato's lead solution. Electron micrographs were taken with a JEM-100C electron microscope.

\section{RESULTS}

\section{Normal untreated rabbit}

As is well known, sinusoidal endothelial cells lack a continuous basal lamina, being composed of a perikaryon and a membraneous extension of cytoplasm which occupies the major part of the sinusoidal lining. The cytoplasmic extension is composed of alternately thicker and thinner portions, the latter comprising sieve plates. These two portions, however, are not disposed so regularly in the rabbit as was first reported by WISSE (1970) in the rat; the disposition varies from place to place as shown in Figures $1 \mathrm{a}$ and $\mathrm{b}$. In agreement with the observations in the guinea pig, the perikaryon and thicker portions of rabbit sinusoidal endothelium reveal relatively large lysosomes, short cisternae of the rough endoplasmic reticulum and free polysomes in considerable numbers. Mitochondria are as small as those of the Ito cell. The electron dense smooth-surfaced tubules (transfer tubules, PRAANING-VAN DALEN et al., 1982) are distributed in moderate numbers, both in the perikaryon and in the thicker portions. The Golgi complex is restricted to the perikaryon on one side of the nucleus. Neither smooth-surfaced pits along the plasma membrane nor smooth pinocytotic vesicles are detectable; instead a number of larger coated pits and coated pinocytotic vesicles are distributed in the perikaryon and in the thicker portions. Macropinocytotic vesicles (WISSE, 1972) and lipid droplets are only rarely revealed in normal control rabbits.

Fat-storing cells (Ito cells) in normal rabbits, as have been demonstrated light microscopically (ITO, 1956) and electron microscopically (SHIBASAKI, 1982), are generally characterized by numerous small lipid droplets densely filling the cytoplasm (Fig. 2), although their amount varies from cell to cell to where occasional showing a 
so-called empty fat-storing cells are seen. In the well-fed control rabbits, a considerable amount of glycogen was demonstrated light microscopically (ITO et al., 1953) among lipid vacuoles; the electron microscope showed glycogen $\beta$-particles concentrated along the surfaces of the lipid droplets (Fig. 2) as also noted by SHIBASAKI (1982). Lipid droplets surrounded by glycogen particles are revealed also in the cytoplasmic

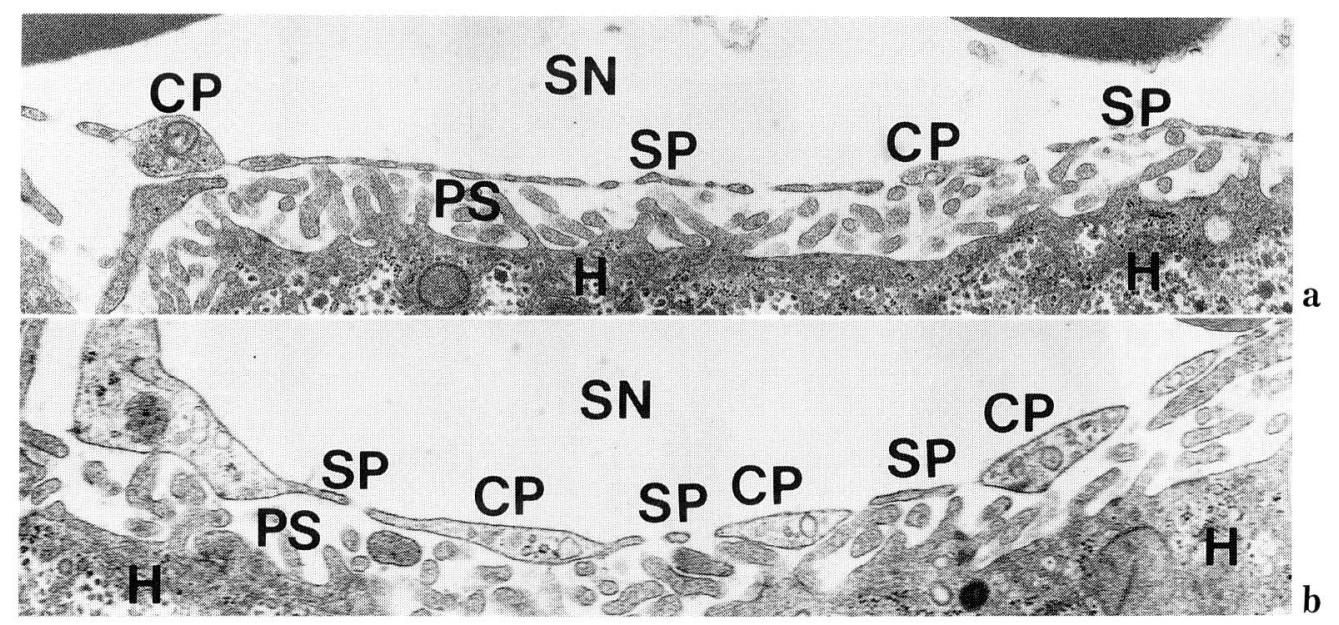

Fig. 1. a and b. Variable proportions of the thicker $(C P)$ and thinner portions including sieve plates $(S P)$ in the endothelial lining of the sinusoid $(S N)$ in a control rabbit. $H$ hepatocyte, $P S$ Disse's space. a : $\times 13,300, \mathrm{~b}: \times 16,800$

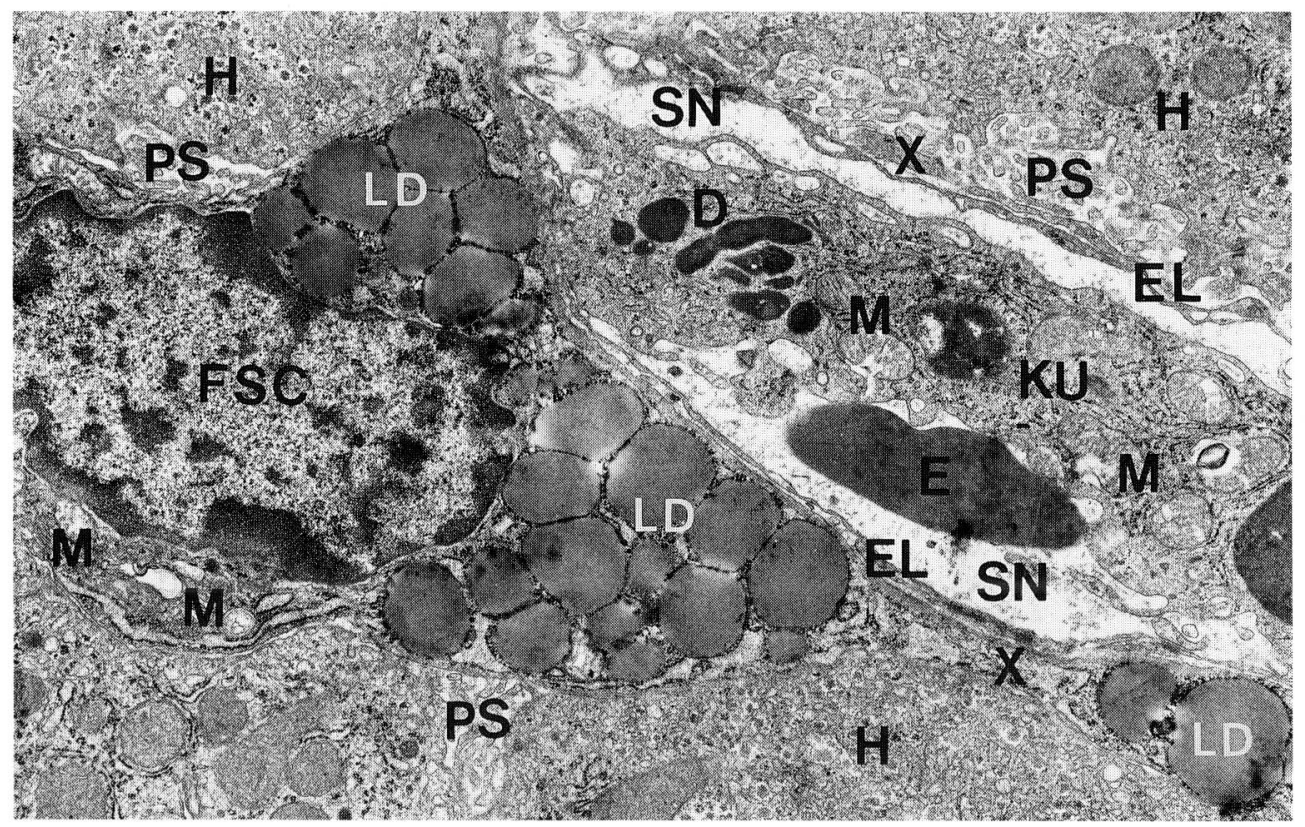

Fig. 2. Fat-storing cell $(F S C)$ filled with small lipid droplets $(L D)$ rimmed by glycogen $\beta$-particles which are distributed also in a cytoplasmic process $(X)$. D lysosomes, $E$ erythrocyte, $E L$ endothelial lining of the sinusoid $(S N), H$ hepatocytes, $K U$ Kupffer cell, $M$ mitochondria, $P S$ Disse's space. Control rabbit. $\times 10,000$ 
processes protruding along the sinusoidal endothelial lining (Fig. 2, 4). Other ultrastructural characteristics of the Ito cell are also demonstrated: lack of the basal lamina, well-developed rough endoplasmic reticulum, small scanty mitochondria, and single cilia extended from the distal centriole of the diplosome within the Golgi complex.

As in other mammals, the Kupffer cells of the rabbit are rich in cytoplasm and bulge well into the sinusoidal lumen; they are characterized by a large amount of organelles, especially lysosomes, large mitochondria and worm-like structures (Fig. 2, 4). The worm-like structures, which are characterized by a median dense line, occasionally show a complicated system occupying a large area of the cytoplasm as in the guinea pig Kupffer cell (OHATA et al., 1984).

Meandering canaliculi and pored domes are detected only sporadically in the

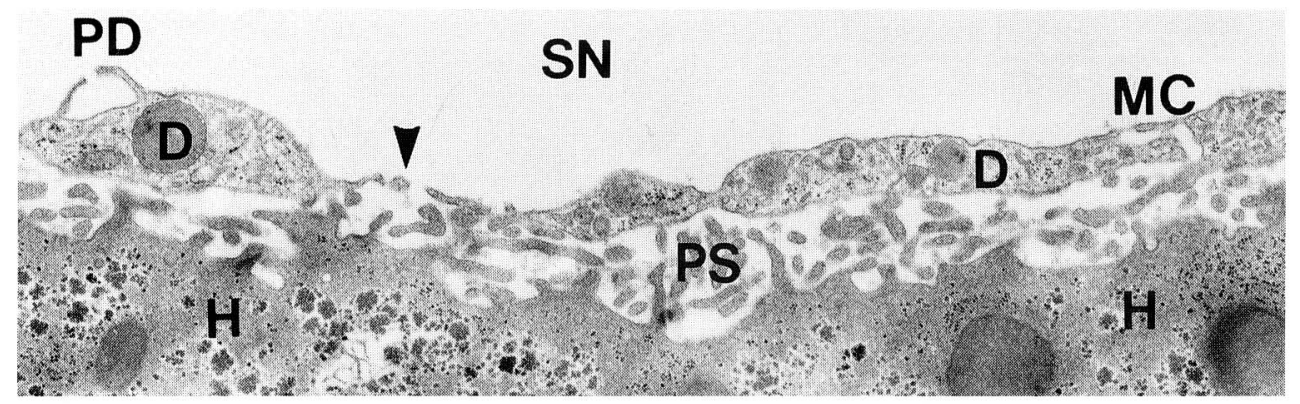

Fig. 3. A part of the sinusoidal endothelium with its thicker portions containing lysosomes $(D)$ and a thinner portion including a sieve plate (arrowhead). A small pored dome $(P D)$ is shown on a thicker portion on the left side. On the right side, a rudimental canaliculus $(M C)$ is seen with openings both to the sinusoid $(S N)$ and to the Disse's space $(P S) . H$ hepatocyte. Control rabbit. $\times 13,800$

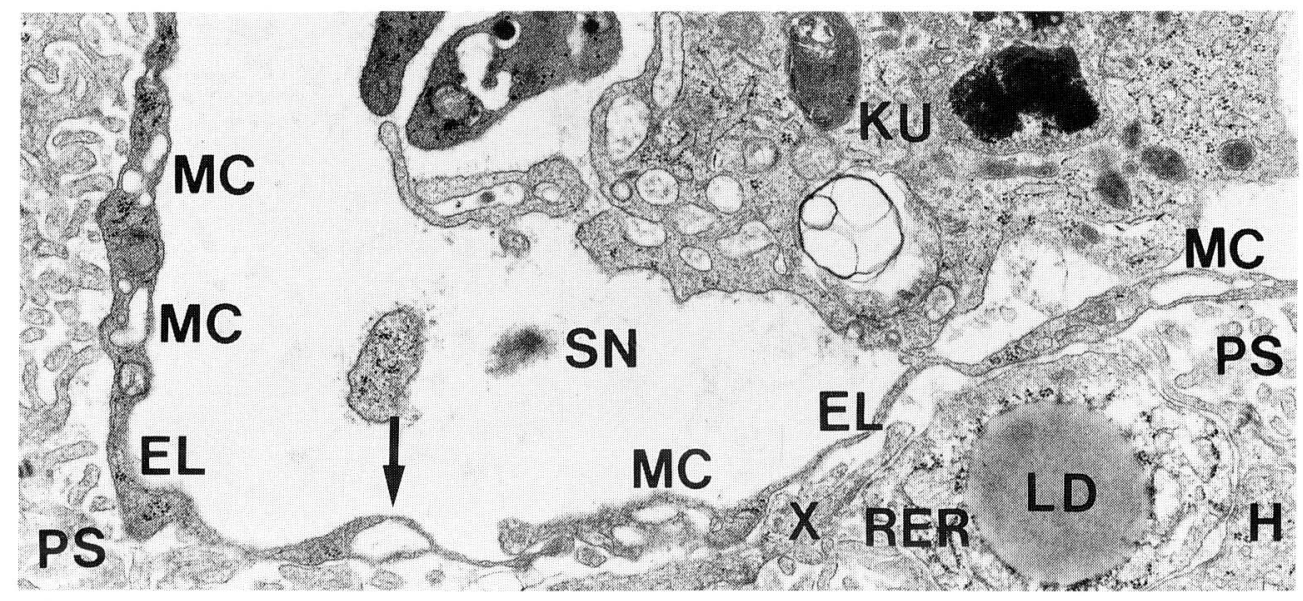

Fig. 4. Endothelial lining $(E L)$ of a sinusoid $(S N)$ composed of thinner and thicker portions. The thicker portions contain segments of rudimentary meandering canaliculi $(M C)$ lacking in openings. Among them a pored dome-like vacuole (arrow) is observed. $H$ hepatocyte, $K U$ Kupffer cell with segments of a worm-like structure, $L D$ lipid droplet surrounded by rough endoplasmic reticulum $(R E R)$ in a cytoplasmic process $(X)$ of an Ito cell. PS Disse's space. Control rabbit. $\times 16,800$ 
sinusoidal endothelium in the control rabbits, in contrast to the well-developed structures in normal untreated guinea pigs demonstrated by OHATA et al. (1984). Only rarely can short canaliculi and small pored domes be found in the cytoplasm of the thicker portions of the endothelial cell extension. The short canaliculi penetrate the endothelial cytoplasm with openings both on its sinusoidal and perisinusoidal surfaces (Fig. 3). Furthermore, a number of short curved canaliculi and small vacuoles are occasionally revealed closely side by side in thicker portions of the endothelial extensions without showing any openings either into the sinusoid or into the Disse's space (Fig. 4). These findings suggest the existence of poorly developed, short, meandering canaliculi in the thicker portions of the normal rabbit endothelium.

Very rarely one may encounter short but remarkably thick meandering canaliculi showing simple branching and a vacuolar beaded profile; the canaliculi penetrate across the thicker portion with perisinusoidal and sinusoidal openings (Fig. 5).

\section{Rabbits treated in winter}

In the animals experimentally treated in winter well-developed meandering canaliculi were frequently encountered in the sinusoidal endothelium in four out of the five

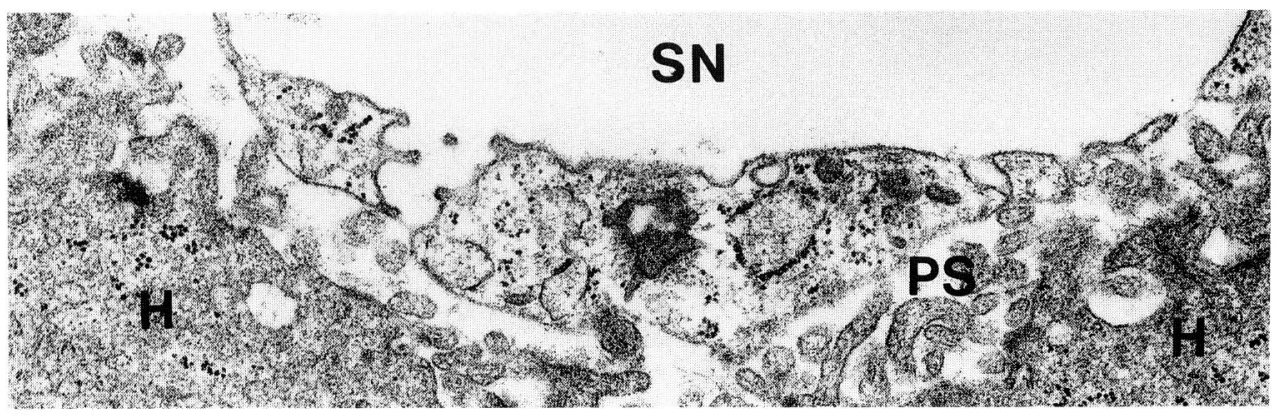

Fig. 5. A well-developed, but short-branched meandering canaliculus penetrating a thicker portion with two sinusoidal orifices and a single perisinusoidal one. $H$ hepatocyte, $P S$ Disse's space, $S N$ sinusoid. Control rabbit. $\times 24,000$

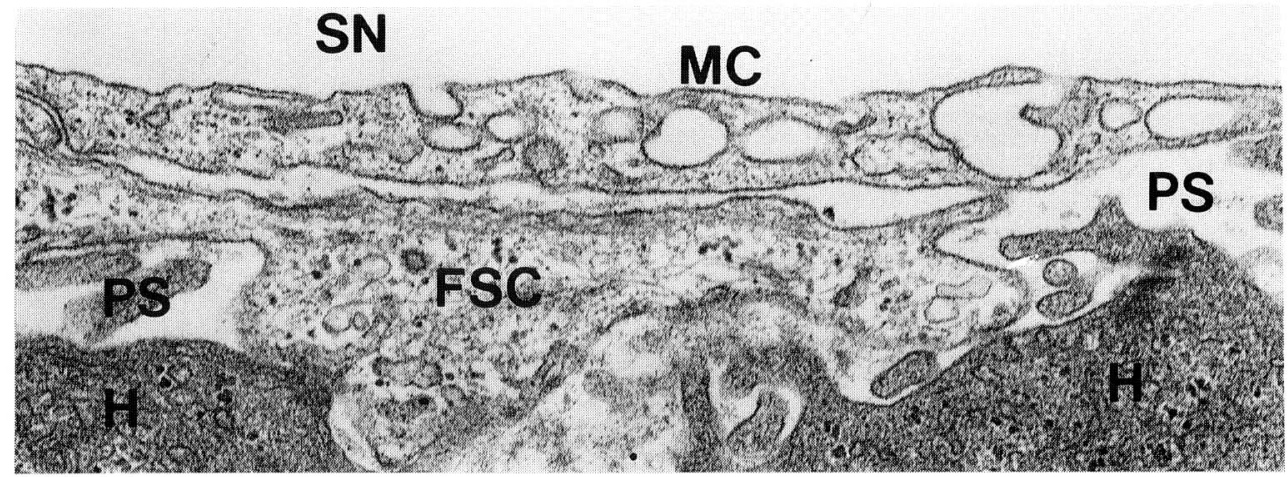

Fig. 6. A well-developed meandering canaliculus $(M C)$ with conspicuously expanded portions extended along the thicker portion of the endothelial lining. FSC Ito cell, $H$ hepatocyte, PS Disse's space, $S N$ sinusoid. Rabbit subjected to experimental treatment in winter. $\times 32,500$ 


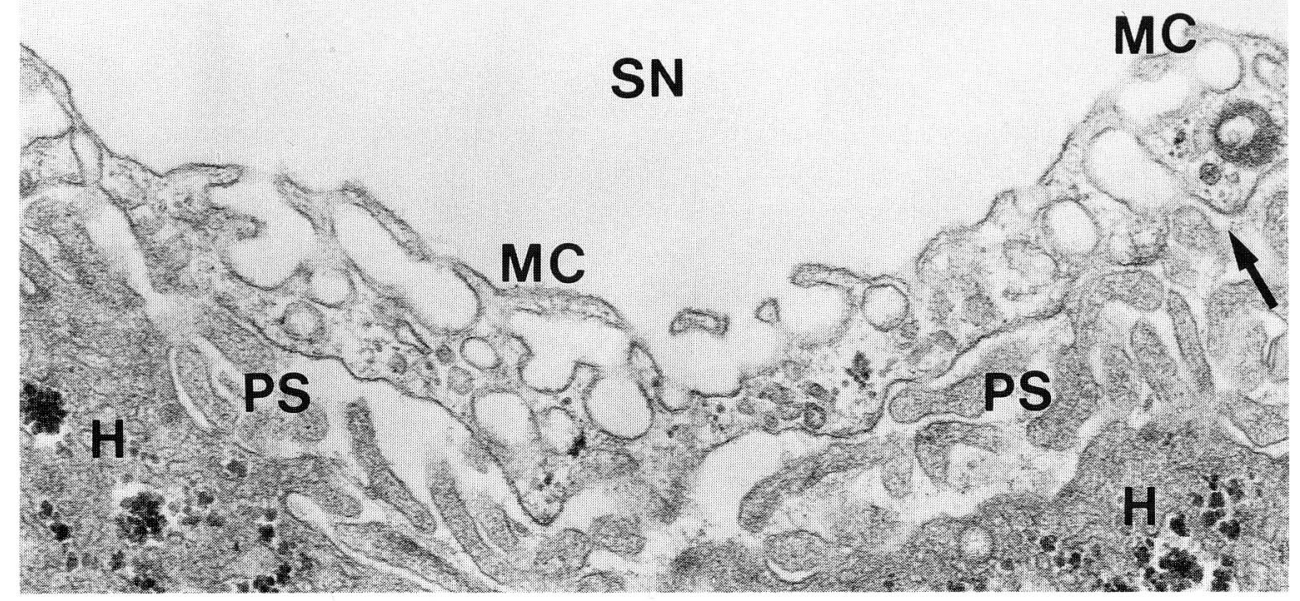

Fig. 7. Well-developed meandering canaliculus $(M C)$ with vacuolar expansions and constrictions running along a thicker portion, with a thin fenestrated sinusoidal wall penetrated by many openings to the sinusoid $(S N) . \quad H$ hepatocyte, $P S$ Disse's space; the arrow indicates a perisinusoidal opening. Rabbit subjected to experimental treatment in winter. $\times 33,800$

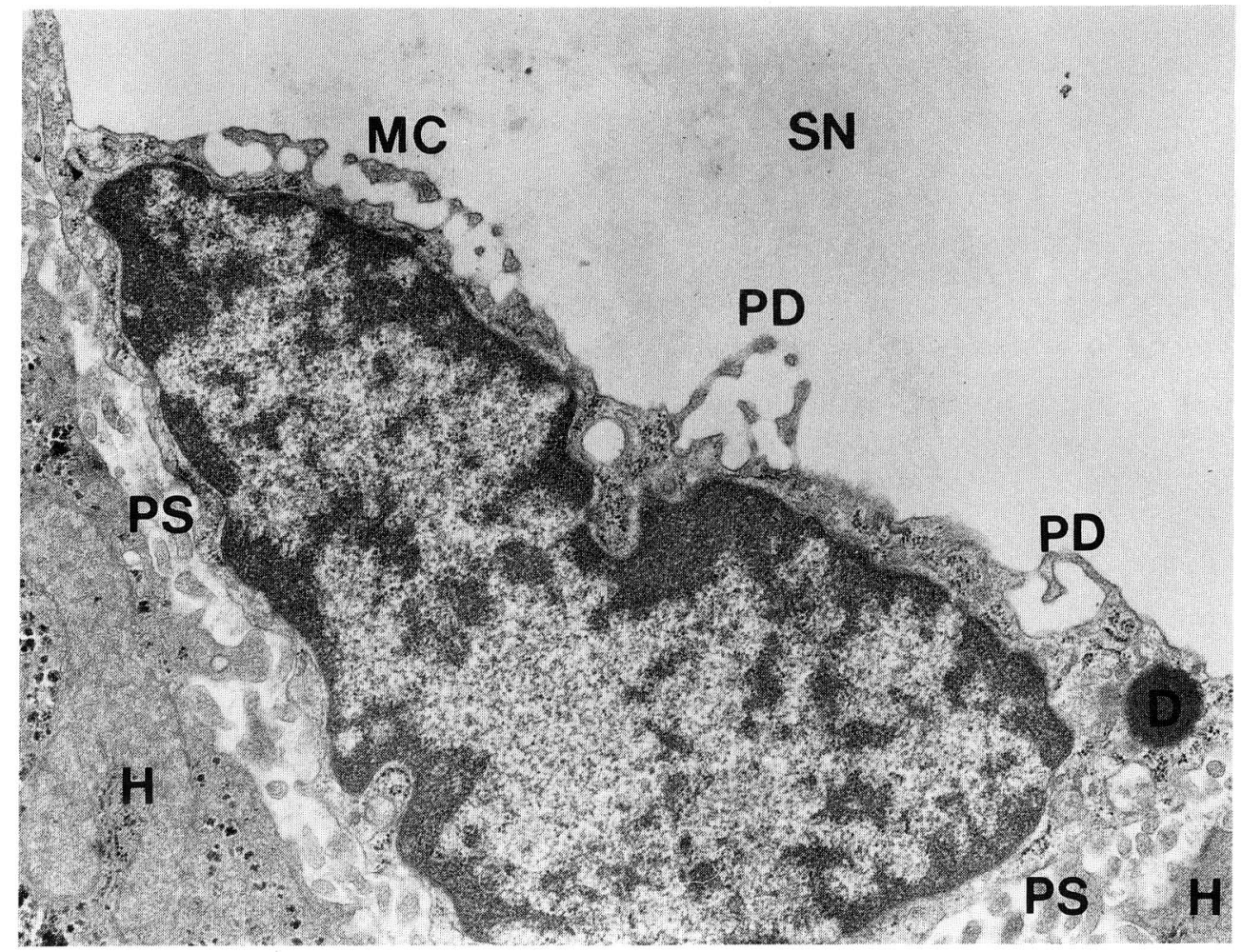

Fig. 8. An endothelial perikaryon showing, on the left side, a meandering canaliculus $(M C)$ running along the nucleus leaving a thin fenestrated sinusoidal wall and two pored domes $(P D)$ on the right side. $D$ lysosome, $H$ hepatocyte, $P S$ Disse's space, $S N$ sinusoid. Rabbit subjected to experimental treatment in winter. $\times 17,400$ 


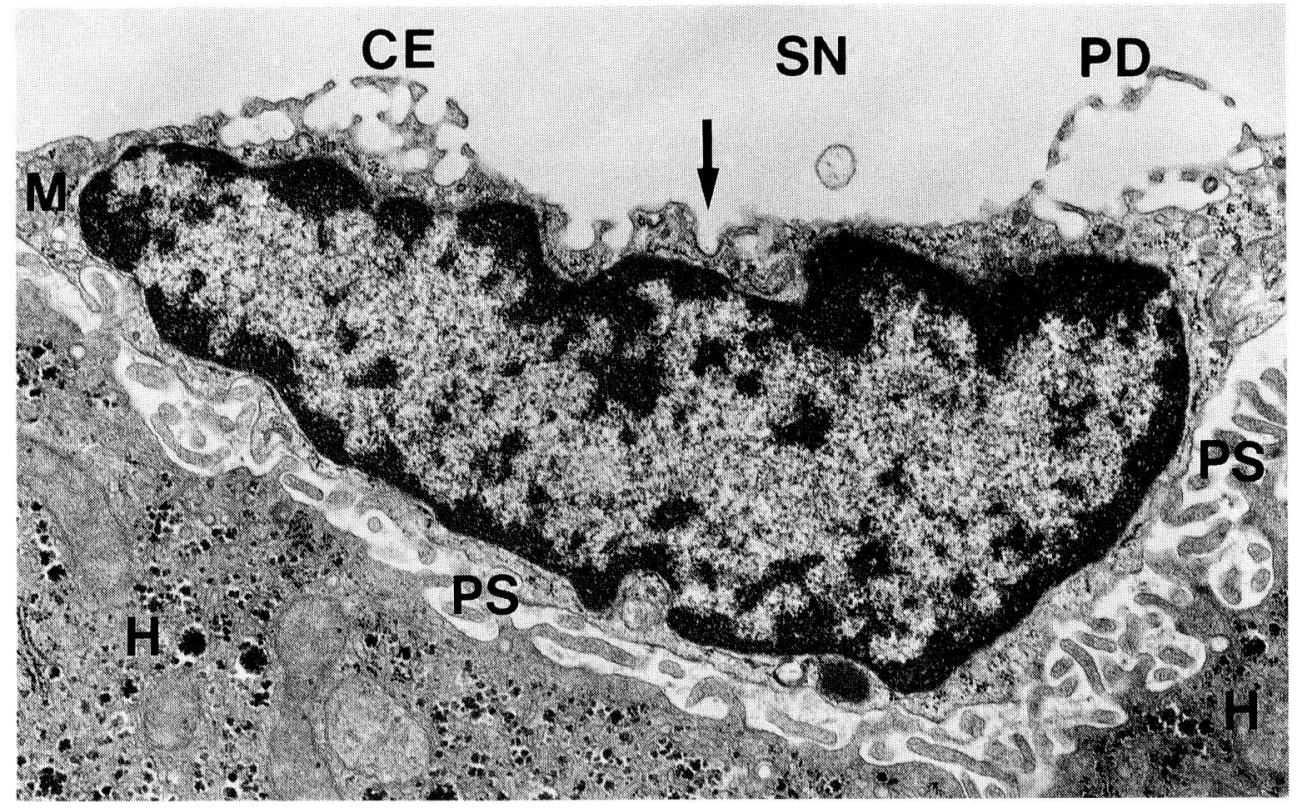

Fig. 9. An endothelial perikaryon showing a pored dome $(P D)$ bulging into the sinusoid $(S N)$ on the right side. A cytoplasmic eminence $(C E)$ on the left side contains a network of meandering canaliculi with sinusoidal openings. The cavity of the pored dome is divided into compartment by pored laminae. $H$ hepatocyte, $M$ mitochondria, $P S$ Disse's space; the arrow indicates a coated pit. Rabbit subjected to experimental treatment in winter. $\times 17,000$

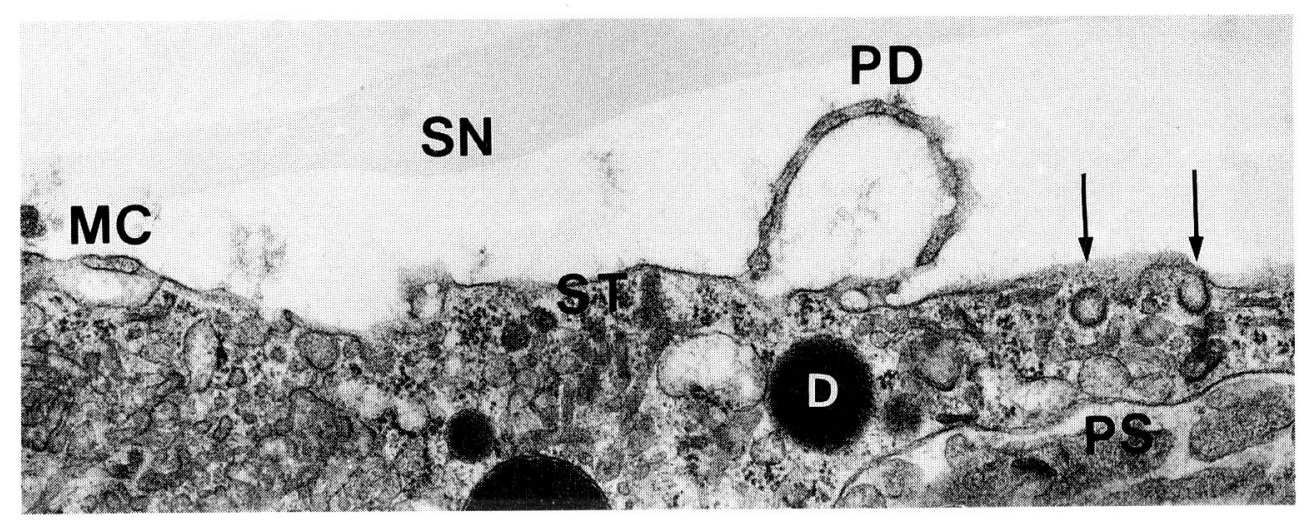

Fig. 10. A large typical pored dome $(P D)$ bulging into the sinusoid $(S N)$ from the transitional portion between the perikaryon and the cytoplasmic attenuation of an endothelial cell. A single large cavity of the dome is covered by a thin pored sheet. $D$ lysosome, $M C$ meandering canaliculus; the arrows indicate coated vesicles; $P S$ Disse's space, $S T$ dense smooth-surfaced tubuli. Rabbit subjected to experimental treatment in winter. $\times 25,000$ 
specimens. The meandering canaliculi, varying from 50 to $200 \mathrm{~nm}$ in diameter with the mean at about $130 \mathrm{~nm}$, run roughly along the long axis of the thicker portions. They exhibit vacuolar expansions and constrictions in profile as shown in Figures 6 and 7 , and possess plural openings or fenestrations often communicating with the sinusoidal lumen, but less frequently with the Disse's space. As seen in Figure 7, the thin cytoplasmic sheets separating the canaliculi from the sinusoidal lumen simulate the sieve plates, as evidenced by the occurrence of many sinusoidal openings or fenestrations.

In the rabbits experimentally treated in winter, the meandering canaliculi may also occur in the perikaryonal cytoplasm, sometimes together with the pored dome.

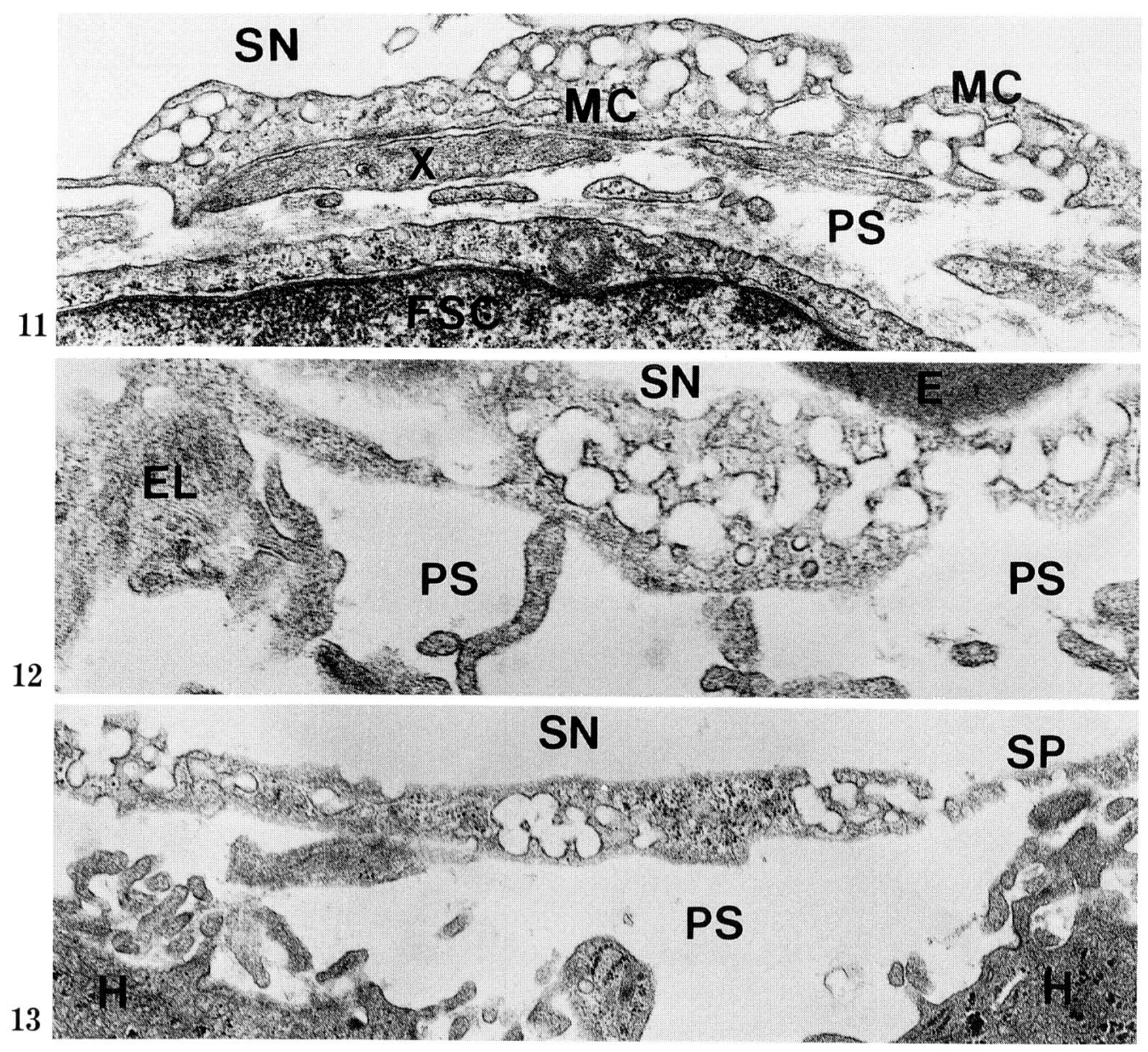

Fig. 11-13. Network of meandering canaliculi $(M C)$ with vacuolar expansions and constrictions revealed in the enlarged thicker portions of the endothelial extensions. The canalicular system communicates openings both to the sinusoid $(S N)$ and to the Disse's space $(P S)$. E erythrocyte, $E L$ endothelial lining, FSC fat-storing cell with a subendothelial process $(X), H$ hepatocyte, $S P$ sieve plate. In Fig. 13, three small networks of the meandering canaliculi are distributed at short intervals in an elongated thicker portion. Rabbits subjected to experimental treatment in winter. Fig. 11: $\times 25,000$, Fig. $12: \times 32,000$, Fig. $13: \times 20,000$ 
The occurrence of the perikaryonal canaliculi is less frequent as compared with those found in the thicker portions. When the cytoplasmic layer is relatively thin, the unbranched canaliculus is elongated along the sinusoidal surface of the nucleus, showing alternating expansions and constrictions (Fig. 8), and its thin sinusoidal wall is densely interrupted by small openings pouring into the sinusoid, exhibiting a sieve plate-like profile. When the perikaryonal cytoplasm has accumulated to form a low eminence bulging into the sinusoid, the branched meandering canaliculi contained in it make a network which communicates with the sinusoid by a crowd of many small openings, thus presenting a sieve plate appearance (Fig. 9). The meandering canaliculi on the sinusoidal surface of the perikaryon of the endothelial cell may communicate with those on the cytoplasmic extensions and/or with those on the perisinusoidal surface of the perikaryon as shown in Figure 16. Through these canalicular communications the meandering canaliculi of the perikaryon may ultimately pour themselves

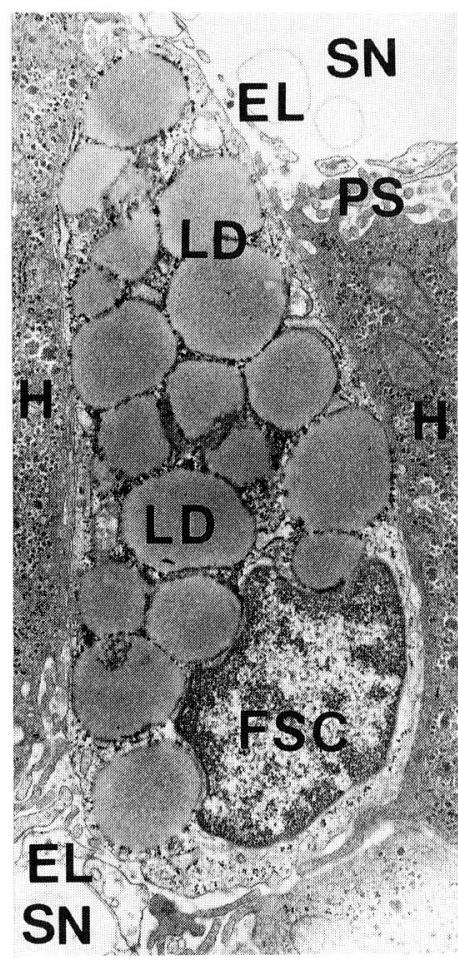

Fig. 14. A fat-storing cell $(F S C)$ from a rabbit subjected to experimental treatment in winter. The amount of small lipid droplets $(L D)$ consumed by long-term starvation has already been considerably recovered and glycogen particles are concentrated along their surface. EL endothelial lining of the sinusoid (SN), $H$ hepatocyte, $P S$ Disse's space. $\times 10,000$ into the Disse's space, or vice versa.

The pored domes (FujITA) are observed, bulging rather strikingly into the sinusoid (Fig. 8, 9). The convex, thin cytoplasmic sheet covering the sinusoidal surface of the dome is always fenestrated like a sieve plate. Its interior is divided into irregular cavities by a three-dimensional network of pored plates. A simple and typically large pored dome is also occasionally found in the transitional portion between the perikaryon and the cytoplasmic extension (Fig. 10). A single spacious cavity contains no structure and is separated from the sinusoid by a thin pored sheet.

The most complicated meandering canaliculi detected in the thicker portions of the endothelial extension of the rabbits treated in winter are shown in Figures 11 and 12. They exhibit alternately expanded and constricted portions, and form a network by anastomosing with each other. They are densely gathered in the cytoplasm of the thicker portions. The canalicular network shows a sponge-like appearance, opening at random places both into the sinusoid and into the Disse's space (Fig. 11, 12). Simpler and smaller networks of meandering canaliculi are shown in Figures 13.

When rabbits in winter are suddenly fed after a week's starvation and then sacrificed after $20 \mathrm{hr}$, Ito cells already show a remarkable recovery from the waste induced by the fasting (Fig. 14) as has been noted by SATsuKI (1955). Small lipid droplets are considerably increased in number, moderately packing the cytoplasm, and glycogen $\beta$-particles surrounding the lipid droplets are also strikingly augmented, suggesting the recovered ability to actively synthesize lipid from carbohydrate.

In hepatocytes, glycogen particles are also remarkably accumulated throughout the cytoplasm, 
and hypertrophy and hydropic swellings in some mitochondria are noticed, indicating an elevated hepatic function.

\section{Rabbits treated in summer}

During summer, five rabbits were subjected to the same experimental treatment as in winter, and sacrificed after 20 or $24 \mathrm{hr}$. Essentially none of the well-developed meandering canaliculi or pored domes worthy of report could be found, either in the thicker portions or perikaryon of the sinusoidal endothelium. Figure 15 shows an exceptionally well-developed canaliculus measuring roughly $100 \mathrm{~nm}$ in diameter. It is beaded in profile, with vacuolar expansions and constrictions (thick portions measuring roughly $100 \mathrm{~nm}$ ), and runs along the long axis of a thicker portion; it is separated by a fenestrated sheet from both the sinusoidal lumen and the Disse's space. The fenestrae represent the orifices of the canaliculus to the sinusoid or to the Disse's space. Figures $15 \mathrm{a}$ and $\mathrm{b}$ are from two adjacent serial sections, showing an attenuated margin of a perikaryonal cytoplasm and the successive thicker portion of the cytoplasmic extension. This canaliculus, running longitudinally in the thicker portion, seems to communicate with a short canaliculus present in the adjacent attenuated margin of the perikaryon which opens into the Disse's space. Another short, thicker portion present on the left side beyond a thinner portion is penetrated by short meandering canaliculi which join the sinusoid and the Disse's space.

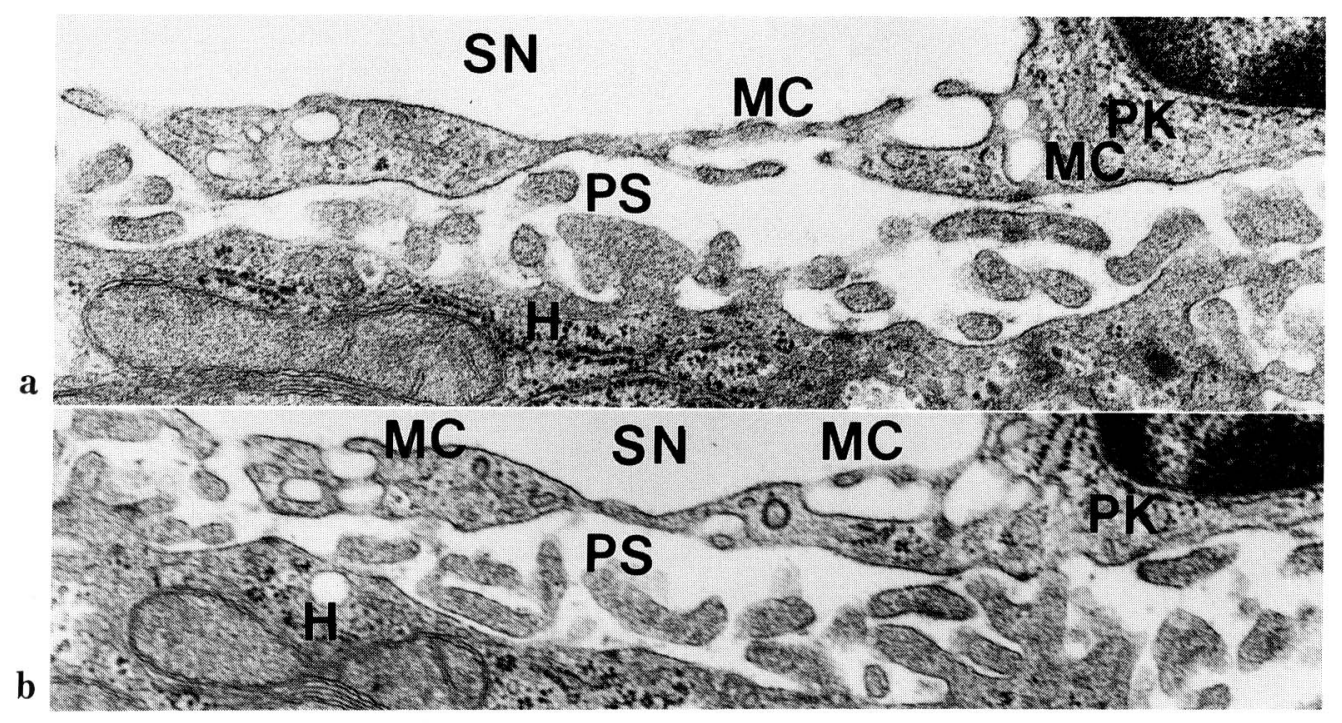

Fig. 15. An attenuated margin of the endothelial perikaryon $(P K)$ and two subsequent thicker portions intervened by a short thinner portion, as seen in the two successive sections. a. Across the transitional portion between the perikaryon and the thicker portion, a meandering canaliculus $(M C)$ is present communicating the sinusoid (SN) and the Disse's space $(P S)$. This is also continuous with the longitudinal meandering canaliculus $(M C)$ running in the thicker portion with fenestrated sinusoidal and perisinusoidal walls. b. Across the second thicker portion, a short meandering canaliculus is visible communicating the sinusoid $(S N)$ and the Disse's space (PS). $H$ hepatocyte. Rabbit subjected to experimental treatment in summer. a and b : $\times 26,000$ 


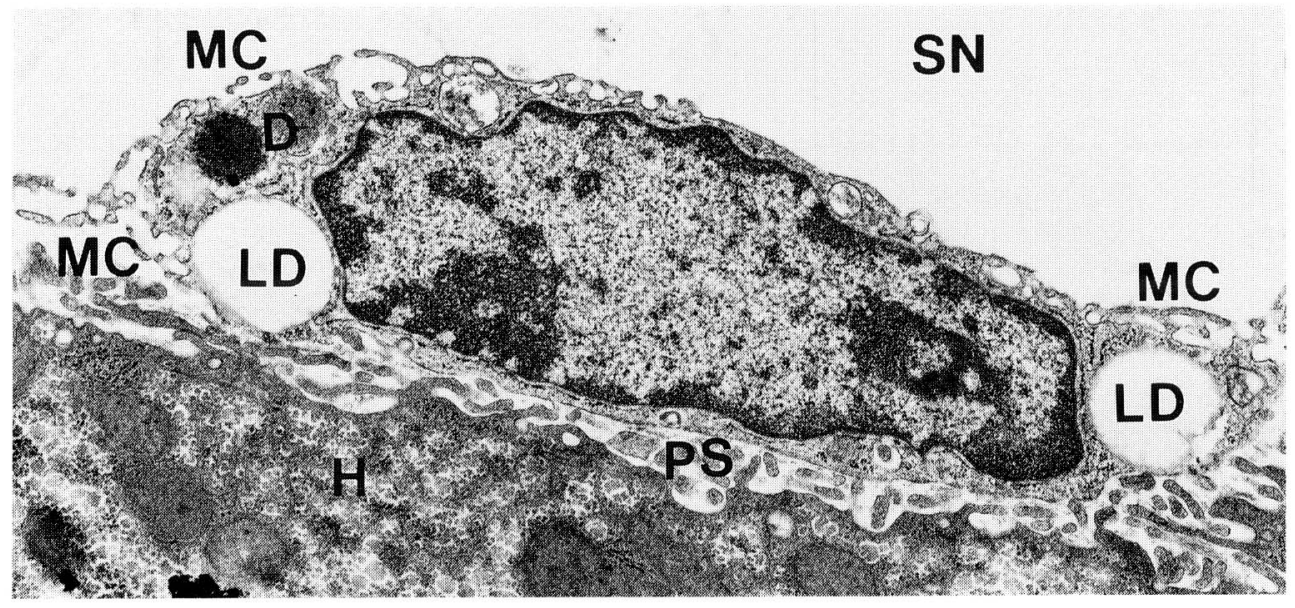

Fig. 16. Meandering canaliculi $(M C)$ along the sinusoidal surface of an endothelial perikaryon. In both margings of the perikaryon, they communicate with a meandering canaliculus $(M C)$ present in the perisinusoidal aspect of the perikaryon and with the meandering canaliculus $(M C)$ present in the thicker portion abutting on the perikaryon to, in both cases, pour themselves, into the Disse's space $(P S)$. In either marginal part of this perikaryon a lipid droplet (vacuole, $L D$ ) is present. $H$ hepatocyte, $S N$ sinusoid. Rabbit subjected to experimental treatment in winter. $\times 13,300$
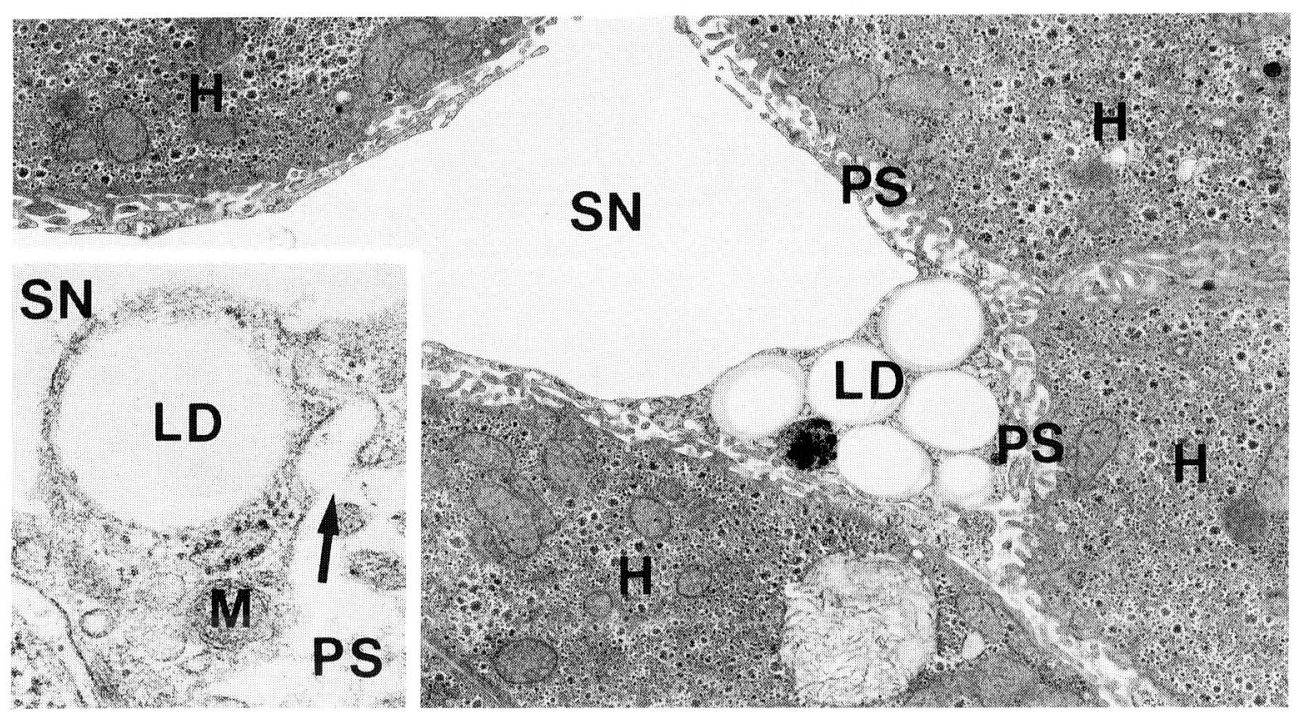

Fig. 17. Accumulation of lipid droplets $(L D)$ in the perikaryonal cytoplasm of a sinusoidal endothelium. $H$ hepatocyte, $P S$ Disse's space, $S N$ sinusoid. Rabbit subjected to experimental treatment in winter. $\times 7,000$. Inset. A higher magnification of a lipid droplet $(L D)$ in the thicker portion which shows the absence of the limiting membrane in the droplet. The arrow indicates a canaliculus curved spirally along the droplet communicating the sinusoid $(S N)$ and the Disse's space $(P S) . M$ mitochondria. Rabbit subjected to experimental treatment in winter. $\times 40,200$ 
In the rabbits experimentally treated in summer and sacrificed 20 or $24 \mathrm{hr}$ after resumption of feeding, the recovery of Ito cells from consumption induced by lengthy starvation has not been established. This means that the amount of their lipid droplets has not yet been remarkably increased; in particular, glycogen $\beta$-particlerims of the lipid droplets are hardly demonstrated. The recovery of glycogen particles in hepatocytes is also insufficient.

\section{Lipid droplets in endothelial cells}

In the hepatic sinusoidal endothelial cells of the normal control rabbits, no lipid droplets are demonstrated. In some rabbits subjected to the experimentation in winter, lipid droplets (vacuoles) are revealed both in the perikaryonal cytoplasm and in the thicker portion of the sinusoidal endothelial cells. In the perikaryon depicted in Figure 16, one lipid vacuole is seen in each attenuated margin of the perikaryon, while in occasional cases many lipid vacuoles fill the perikaryonal cytoplasm (Fig. 17). The lipid droplets lacks a limiting membrane, as shown in the inset of Figure 17.

In the rabbits subjected to the same experimental treatment in summer, no lipid droplets appeared in the hepatic sinusoidal endothelium.

\section{DISCUSSION}

Different from the normal guinea pig livers in which the sinusoidal endothelial cells exhibit well-developed meandering canaliculi and pored domes as was recently reported by OHATA et al. (1984), the normal control rabbit livers examined in the present study show only rudimentary channels or small vacuoles which may correspond to underdeveloped canaliculi and occasional small pored domes in the thicker portions of the sinusoidal endothelial extensions. For the purpose of inducing better formation of the canaliculi and domes in rabbits, we subjected the animals to experimental conditions which might possibly bring about rapid and strong functional changes in the liver inclusive of an accelerated sinusoidal microcirculation. Rabbits were completely deprived of food for one week, allowed to eat for a day, and then sacrificed (SATSUKI, 1955).

In the livers of the rabbits thus treated in winter, we could frequently observe well-developed meandering canaliculi often comprising as a whole sponge-like canalicular networks, and exhibiting structural properties similar to those in normal guinea pigs. They showed vacuolar expansions alternating with constrictions and, provided with plural openings, they poured themselves both into the sinusoid and into the Disse's space. Accordingly, the thin sinusoidal wall of the canaliculi interrupted by these openings exhibited a sieve plate-like appearance.

Differing from the channels produced by linked pinocytotic vesicles across the capillary endothelial wall elsewhere (KOBAYASHI, $1970 \mathrm{a}, \mathrm{b}, \mathrm{c}$ ), diaphragms have been confirmed neither at the orifices nor at the constrictions of the hepatic sinusoidal endothelial canaliculi. Short, straight or curved canaliculi penetrating the thicker portion of the endothelium were also observed. The true sieve plates restricted to the thinner portions were observed alternately with the thicker portions without showing any morphological changes induced by the experimental procedures.

In the livers from the rabbits treated in winter, meandering canaliculi and pored domes on the perikarya of the sinusoidal endothelium were revealed more frequently than in the normal guinea pigs. These canaliculi were provided with an ultrastructure 
identical to that of the thicker portions.

The pored domes were discovered by FujITA and his collaborators (FUJITA et al., 1976 ; YOSHINARI and FUJITA, 1982) using the SEM in the fenestrated endothelial sheet and on the perikaryonal swelling in the rat and rabbit renal glomeruli. Their occurrence was also confirmed on the perikaryon of the hepatic sinusoidal endothelium in the crab-eating monkey (TANUMA et al., 1983) and guinea pig (OHATA et al., 1984). In the livers from the above mentioned rabbits treated in winter, we frequently found these domes on the sinusoidal surface of the perikarya, bulging rather strikingly into the sinusoid. As observed with the TEM, the majority of them contained generally complicated interior structures which were not detected in the livers of the monkey (TANUMA et al., 1983) or guinea pig (OHATA et al., 1984).

The same experimental treatment carried out on five rabbits in summer failed to produce evidence of the canalicular structures in the sinusoidal endothelium, except for occasional inconspicuous canaliculi. To investigate seasonal changes in the hepatic function of the rabbit, experimental cytochemical examinations on the glycogen metabolism in the rabbit hepatocyte had previously been made once a month throughout a year, from which we obtained evidence supporting that the hepatocyte function participating in glycogen metabolism might undergo a definite seasonal variation (ITO et al., 1960), being suppressed in summer, especially in August. The unexpected results in the "summer rabbits" in the present study might possibly be related to the summer time inhibition of the hepatic function.

It has been elucidated by the present study that the meandering canaliculi and pored domes might be constant rather then incidental structures in the sinusoidal endothelium of rabbit livers. Although they remained underdeveloped and rudimentary structures under normal conditions, the experimental treatment, i. e., feeding after long-term starvation caused a conspicuous development of both structures. The meandering canaliculi were increased in length and caliber, showing numerous openings both to the sinusoid and to the Disse's space. In addition, similar canaliculi and pored domes developed in the perikaryonal cytoplasm.

The conspicuous canalicular development in the thicker portions of the sinusoidal endothelial extension and in the perikaryonal cytoplasm can probably be ascribed to the suddenly elevated hepatic function arising from the resumption of feeding. Careful observations of the electron micrographs indicate that the thicker portions are also developed, being more or less elongated and thickened to accommodate themselves to the enlarged canalicular system, to then be embraced by them.

In the elevated functional state of the liver, the amount of the blood flow in the sinusoid might be increased in direct proportion with the portal hypertension. The conspicuous development of the meandering canaliculi in the thicker portions of the sinusoidal endothelium in the treated rabbits may probably relate to the disposal of the blood overflow in the sinusoid.

Recent immunohistochemical studies by TSUCHIYA et al. (1984), and ODA et al. (1985), have revealed actin filaments in the cytoplasm of hepatic sinusoidal endothelium which might actively participate in the control of the self contraction and dilation both of the sinusoid and of the fenestrae of the sieve plate. Using rat livers, TsuchIYA and his collaborators carried out morphometric analysis in scanning electron micrographs, demonstrating that the fenestrae of the endothelial extensions actively constrict in the case of a decrease in the sinusoidal blood flow, and actively dilate in the case of an increase in the blood flow. They seemed to lay stress on the role of the fenestrae and sieve plates in the regulation of the sinusoidal blood flow. According to the study by 
Tsuchiy et al. (1984), the blood pressure of the sinusoid measures $7 \mathrm{~cm} \mathrm{H}_{2} \mathrm{O}$ at the beginning part adjacent to the portal tract, and $3 \mathrm{~cm} \mathrm{H}_{2} \mathrm{O}$ at the end part adjacent to the central vein. To maintain a smooth blood flow in the sinusoid, it might be necessary to keep this blood pressure gradient. In the present experimental treatment applied to the rabbits, the resumption of feeding seems to have caused an acute overflow of the sinusoidal blood in consequence of the portal hypertension, so that the sieve plates and fenestrae present in the sinusoidal endothelial lining might become insufficient for regulating the sinusoidal blood pressure to maintain the normal gradient of the blood pressure towards the central vein. The meandering canaliculi and pored dome may thus be rapidly elaborated in the endothelial cytoplasm in accordance with this need to supplement the regulatory function of the sieve plates and fenestrae of the endothelial lining. The actively absorb excessive blood plasma from the sinusoid for temporary storage in them and then leak it gradually into the Disse's space. From the above arguments, the reason why the well-developed meandering canaliculi occur in the thicker portions of the normal guinea pig liver may be accounted for as follows : in this species the canalicular apparatus in the thicker portion must always be well developed in the physiological state to maintain smooth blood flow in the sinusoid supplementing the species-specific weak regulatory function of the sieve plates.

As to the origin of the pored domes which are mainly formed on the perikaryon, the assumption that they are derived from the fusion of meandering canaliculi filling small eminences of the perikaryonal cytoplasm seems most plausible.

Many authors have reported that in the cytoplasm (endoplasm) of isolated, cultured and free rounded-up endothelial cells from rat and mouse hepatic sinusoids, there appeared a "network of tortuous canaliculi with vacuolar expansions" provided with many openings to the outside of the cell (DROCHMANS et al., 1977 ; DE LEEUW et al., 1982 ; GARVEY and CAPERNA, 1982 ; MONTECINO-RODORIGUES et al., 1982 ; NAGELKERKE et al., 1982; Roos et al., 1982). As to the origin of these canalicular structures in isolated rodent endothelial cells, OHATA et al., (1984) pointed out that these structures were produced in the isolated and contracted endothelial cells, and they originated not only from the fenestrae of the sieve plates but also from meandering canaliculi and pored domes, which proved to be preexisting structures in guinea pig livers.

But, in considering rat and mouse livers, whether or not the meandering canaliculi and pored domes may preexist in the normal states remains unsolved. WISSE (1970) however, described, in his paper on the sinusoidal endothelial cells of rat liver how : "the sieve plates are not always of the simple, single-layered type, but sometimes, a sponge-like network with no resemblance to single-layered sieve plates" (Fig. 4, p. 132). These findings of Wisse, according to the present authors' view, may be induced by the existence of meandering canaliculi elongated along the thicker portions sometimes forming canalicular networks with numerous openings both into the sinusoid and the Disse's space. Thus, WISSE's observation indicates that the meandering canaliculi do preexist in the sinusoidal endothelium of normal rats. In the present study it has been proved that the underdeveloped and rudimentary meandering canaliculi and pored domes preexist in normal rabbit liver. Therefore, if the normal rabbit sinusoidal endothelium would actually be isolated and cultured, that "network of well-developed tortuous canaliculi with vacuolar expansions" would be found as a consequence of rapid structural development induced by such stimuli as applied during cell isolation and culture. 


\section{REFERENCES}

De Leeuw, A. M., J. E. Martindale and D. L. Knook: Culture and cocultures of rat liver Kupffer, endothelial and fat-storing cells. In: (ed. by) D. L. Knook and E. Wisse: Sinusoidal liver cells. Elsevier Biomedical Press, 1982 (p. 139-146).

Drochmans, P., E. Ch. Sleyster, W. Penasse, J. C. Wanson and D. L. Knook: Morphology of isolated and cultured sinus-lining cells of rat liver. In : (ed. by) E. Wisse and D. L. Knook : Kupffer cells and other sinusoidal cells. Elsevier/Northholland Biomedical Press, Amsterdam, 1977 (p. 131-139).

Fujita, T., J. Tokunaga and M. Edanaga: Scanning electron microscopy of the glomeruler filtration membrane in the rat kidney. Cell Tiss. Res. $166: 299-314$ (1976).

Garvey, J. S. and T. J. Caperna: The role of endothelial cells and Kupffer cells in antigen processing by Fisher-334 rats. In : (ed. by) D. L. Knook and E. Wisse : Sinusoidal liver cells. Elsevier Biomedical Press, 1982 (p. 421-428).

Ito, T. : Fat-storing cell of the liver-a review. Recent advances in basic medicine. Part of anatomy and pathology. (In Japanese) Ishiyaku Publisher, Tokyo, 1956 (p. 503-554).

Ito, T., S. Shibasaki and T. Kitamura: Experimentell-morphologische Untersuchungen über die jahreszeitlichen Veränderungen der Leberfunktion bei dem Säuger. Hungerversuche an den Kaninchen (Japanese text with German abstract). Arch. histol. jap. 20 : 629-654 (1960).

Ito, T., R. Tahira and K. Tsunoda : Über das Vorkommen des Glykogens in den Fettspeicherungszellen (fat-storing cells) der normalen Kaninchenleber. (Japanese text with German abstract). Arch. histol. jap. 5 : 541-553 (1953).

Kobayashi, S.: Occurrence of unique colloidal particles in snake blood and their transport across the capillary wall. A proposal of a new hypothesis on the permeability of the blood capillaries. Arch. histol. jap. 31 : 511-528 (1970a).

: Ferritin labeling in the fixed muscle capillaries. A doubt on the tracerexperiments as the basis for the vesicular transport theory. Arch. histol. jap. 32 : 8186 (1970b).

: Passage for substance across the endothelial wall of the blood capillaries (In Japanese). Igaku-no-Ayumi 751 p. 469-474 (1970c).

Montecino-Rodoriguez, F., J. L. Gendrault and A. Kirn: Cytochemical study of peroxidase activity in Kupffer (KC) and endothelial cells (EC) isolated from rat and mouse liver. In : (ed. by) D. L. Knook and E. Wisse : Sinusoidal liver cells. Elsevier Biomedical Press, 1982 (p. 489-491).

Nagelkerke, J. F., K. P. Barto and van T. J. C. Berkel: Receptor-mediated endocytosis in rat liver non-parenchymal cells. An evaluation of two recently developed cell isolation procedures. In : Ibid. 1982 (p. 319-326).

Oda, M., N. Tsukada, K. Komatsu and M. Tsuchiya: Morphology and function of hepatic sinusoidal cells (In Japanese). Kan-Tan-Sui 10: 181-198 (1985).

Ohata, M., Y. Tanuma and T. Ito: A transmission electron microscopic study on sinusoidal cells of guinea pig livers, with special reference to the occurrence of the canalicular system and the "pored domes" in the sinusoidal endothelium. Arch. histol. jap. 47 : 359-376 (1984).

Praaning-van Dalen, D. P., A. M. de Leeuw, A. Brouwer, G. C. F. de Ruiter and D. L. Knook: Ultrastructural and biochemical characterization of endocytic mechanisms in rat liver Kupffer and endothelial cells. In (ed. by) D. L. Knook and E. Wisse: Sinusoidal liver cells. Elsevier Biomedical Press, 1982 (p. 271-287).

Roos, E., A. Tulp, O. P. Middelkoop and I. V. van de Pavert: Interaction between livermetastasizing lymphoid tumor cells and hepatic sinusoidal endothelial cells. In: Ibid. 1982 (p. 147-154).

Satsuki, S.: Experimentelle Untersuhungen über den Einfluss der Fütterung auf die Leber und 
ihre Fettspeicherungszellen (fat-storing cells) bei Hungerkaninchen. (Japanese text with German abstract). Arch. histol. jap. 8: 557-598 (1955).

Shibasaki, S.: Structure and function of the Ito cell (fat-storing cell) with reference to the distribution of the vitamin A-storing cell system in the mammals (In Japanese). Metabolism 19: 23-32 (1982).

Tanuma, Y., M. Ohata and T. Ito: Electron microscopic studies on the sinusoidal cells in the monkey liver. Arch. histol. jap. 46 : 401-426 (1983).

Tsuchiya, M., M. Oda and N. Tsukada: Capillaries in the liver-characteriotics of the hepatic sinusoids and their abnormalities (In Japanese). Cell 17:12-17 (1984).

Wisse, E.: An electron microscopic study of the fenestrated endothelial lining of rat liver sinusoids. J. Ultrastr. Res. 31 : 125-150 (1970). : An ultrastructural characterization of endothelial cell in the rat liver sinusoid under normal and various experimental conditions as a contribution to the distinction between endothelial and Kupffer cells. J. Ultrastr. Res. 38 : 528-562 (1972).

Yoshinari, T. and T. Fujita: Scanning electron microscope studies on rabbits renal glomerulus, with special reference to "podocytic membrane" of Elias and to pored domes on capillary endothelium. Arch. histol. jap. 45: 99-109 (1982).

\author{
田沼 裕 \\ T 173 東京都板橋区加賀 2-11-1 \\ 帝京大学医学部 \\ 解剖学第一講座
}

Dr. Yutaka TANUMA

Department of Anatomy

Teikyo University School of Medicine

Kaga 2-11-1, Itabashi-ku

Tokyo, 173 Japan 